\section{BM Paediatrics Open}

\title{
Survey of nutritional practices during therapeutic hypothermia for hypoxic- ischaemic encephalopathy
}

Beth Hazeldine, ${ }^{1}$ Balamurugan Thyagarajan, ${ }^{1,2}$ Michellee Grant, ${ }^{1}$ Elavazhagan Chakkarapani ${ }^{1,2}$

To cite: Hazeldine $B$, Thyagarajan B, Grant M, et al. Survey of nutritional practices during therapeutic hypothermia for hypoxicischaemic encephalopathy. BMJ Paediatrics Open 2017;1:e000022. doi:10.1136/ bmjpo-2017-000022

- Prepublication history and additional material is available. To view please visit the journal (http://dx.doi.org/10.1136/ bmjpo-2017-000022).

Received 3 April 2017 Revised 6 June 2017 Accepted 7 June 2017

\section{(a) CrossMark}

${ }^{1}$ St Michael's Hospital, University Hospitals Bristol NHS Foundation Trust, Bristol, UK

${ }^{2}$ School of Clinical Sciences, University of Bristol, Bristol, UK

Correspondence to Elavazhagan Chakkarapani; Ela. Chakkarapani@bristol.ac.uk

\section{ABSTRACT}

Objective To evaluate current nutritional practices during and after therapeutic hypothermia (TH) for infants with hypoxic-ischaemic encephalopathy (HIE) in UK neonatal units.

Study design Email survey of neonatal clinicians.

Setting UK neonatal units providing active TH.

Patients Neonates cooled for HIE.

Methods Email survey including questions regarding the timing of starting enteral feeds, volumes, frequency and parenteral nutrition (PN) use and availability of guidelines. Results Forty-nine responses were received (49/69, $71 \%)$. The rate of enteral feeding during $\mathrm{TH}$ and rewarming was $59 \%(29 / 49)$. There was a significant linear trend for the increase in the proportion of units starting enteral feeds $(p=0.001)$ during TH. As compared with post-TH period, significantly lower milk volumes were started during TH (median (range): $7.5 \mathrm{~mL} / \mathrm{kg} /$ day (1.5-24) vs $17.5 \mathrm{~mL} / \mathrm{kg} /$ day $(7.5-30), p=0.0004)$. During TH, breast milk was primarily used by $52 \%$ of units predominantly as 2-3 hourly feeds, and volumes were increased as tolerated in $55 \%$ of units. Only $29 \%$ (14/49) of units used PN, with $86 \%(12 / 14)$ of those offering enteral feeds during PN. Guidelines for feeding during TH were available in 31\% (15/49) of units.

Conclusions Many neonatal clinicians offer enteral feeds predominantly using expressed breast milk, with or without PN, during $\mathrm{TH}$, although with huge variability. The heterogeneity in the nutritional practice underscores the need for assessing the safety of both enteral and parenteral feeding during $\mathrm{TH}$.

\section{INTRODUCTION}

Therapeutic hypothermia $(\mathrm{TH})$ is the current standard treatment for infants with moderate/severe hypoxic-ischaemic encephalopathy (HIE). ${ }^{1}$ Optimum nutrition for these infants during TH has not been clarified. Concerns regarding gut injury in infants with HIE exist because of decreased gut blood flow during perinatal asphyxia and reperfusion, ${ }^{23}$ intestinal damage in animal models of $\mathrm{HIE},{ }^{4}$ necrotising enterocolitis (NEC) and/ or gastrointestinal bleeding in $0.7 \%-3.6 \%$ of cooled infants ${ }^{5-7}$ increased intestinal echogenicity in $78 \%$ of cooled infants, ${ }^{8}$ and reports

\section{What is already known on this topic?}

Therapeutic hypothermia is the current standard treatment for infants with moderate-severe hypoxicischaemic encephalopathy.

- The optimum nutrition regimen for these infants has not yet been clarified.

- Enteral nutrition support was deferred until rewarming phase in the clinical trials of therapeutic hypothermia.

\section{What this study adds?}

Increasingly, minimal enteral feeds are offered during therapeutic hypothermia for infants with hypoxic-ischaemic encephalopathy .

- Breast milk is the most commonly used enteral feed, with a small proportion of units offering donor milk or formula.

- There is no consensus regarding type, volume or frequency of enteral feeds given, or the provision of parenteral nutrition to these patients.

of cooling-induced splanchnic vasoconstriction worsening gut ischaemia. ${ }^{9}$ However TH may reduce gut inflammation and protect against NEC. ${ }^{10}$ Feeding breast milk during TH may improve brain recovery. ${ }^{11-13}$ Parenteral nutrition (PN) may lead to intolerance with hypertriglyceridaemia. ${ }^{14}$ In clinical trials of TH, enteral nutrition support was deferred until after rewarming, potentially missing the benefits of early nutrition. ${ }^{515}$

The TOBY Register handbook recommended introducing enteral feeds cautiously after 24 hours of life during $\mathrm{TH}^{16}$ A survey presented in 2014 reported that $21 \%$ of UK neonatal units offered trophic feeds during $\mathrm{TH}$, but lacked data on when milk was introduced, milk type, volumes, frequency and advancement of feeds. ${ }^{17}$ Given reports of the safety of small-volume enteral feeds during $\mathrm{TH},{ }^{18}$ we hypothesised that rates of enteral 
feeding would have increased. In this study, we aimed to survey clinicians in UK neonatal units providing active TH for determining current nutritional practices during and after TH in infants with HIE.

\section{METHODS}

We conducted a UK-wide email survey of neonatal clinician's opinions on feeding practices during and post-TH. We identified the neonatal units in the UK offering active cooling (as opposed to passive cooling postdelivery) from the TOBY Register ${ }^{7}$ and through the British Association of Perinatal Medicine network pages. Where there was uncertainty as to whether a centre provided $\mathrm{TH}$, we clarified this with the centre directly. As the study sought the opinions of healthcare professionals, it did not require ethics approval. Data collection occurred between April and October 2016.

As no validated questionnaire was available, we developed a questionnaire (see online supplementary file 1) asking participants when enteral feeds were started (responses: day 1, 2 or 3 of cooling, during rewarming and post-rewarming), types of feeds and fluids given (responses: expressed breast milk (EBM), donor breast milk (DBM), formula milk, PN, clear fluids), starting volume $(\mathrm{mL} / \mathrm{kg}$ /day ranges), frequency of feeds (continuous, hourly, 2-3 hourly, 4-6 hourly or demand) and feed advancement (no increase, 24 hourly, 12 hourly, 6 hourly, every feed, other). Data were collected for days 1 , 2 and 3 of TH, rewarming and post rewarming. We asked about feeding in clinical circumstances during $\mathrm{TH}$ that may pose concerns about initiating feeds, including need for inotropic support, severity of HIE and high plasma lactate $(>2 \mathrm{mmol} / \mathrm{L})$. Space was provided for comments. We defined enteral feeds as any milk feed given by mouth or gastric tubes. Days 1, 2 and 3 of cooling were defined as each consecutive 24-hour period from achieving target temperature $\left(33^{\circ} \mathrm{C}-34^{\circ} \mathrm{C}\right)$. 'Therapeutic hypothermia' included days 1, 2 and 3 of cooling. 'Rewarming' was defined as the period when infants are warmed back to normothermia $\left(37+/-0.2^{\circ} \mathrm{C}\right)$. 'Postrewarming' included 24 hours post-TH $(<24$ hours post-TH and $>24$ hours post$\mathrm{TH})$. Nil by mouth (NBM) indicated no enteral feeding.

The questionnaire was piloted among two neonatal consultants. Following feedback, we removed questions on numbers of intensive care beds and clarified that the survey is not pertinent for babies with gastrointestinal concerns. We emailed the questionnaire to lead consultants as a Microsoft Word document attachment with a covering letter. If no response was received, we telephoned the units and completed the survey through responses from either the on-call registrar or nurse in charge, or sought contact details for the lead neonatologist for TH or nutrition, who was then approached by email.

Our primary outcome was the proportion of units starting enteral feeds and/or PN during TH and having a guideline for nutrition. Other outcomes included the

\begin{tabular}{lc}
\hline \multicolumn{2}{l}{ Table 1 Demographics of responding units } \\
\hline Baseline characteristics & Responders n, (\%) \\
\hline $\begin{array}{l}\text { Type of unit } \\
\text { Surgical neonatal intensive care } \\
\text { unit (NICU) }\end{array}$ & $17(35 \%)$ \\
$\begin{array}{l}\text { Medical NICU } \\
\text { Local neonatal unit }\end{array}$ & $26(53 \%)$ \\
$\begin{array}{l}\text { Survey method } \\
\text { Telephone }\end{array}$ & $6(12 \%)$ \\
$\begin{array}{l}\text { Email } \\
\text { Respondents }\end{array}$ & $6(12 \%)$ \\
Consultant & $43(88 \%)$ \\
Registrar on-call & $41(84 \%)$ \\
Nurse in charge & $2(4 \%)$ \\
Research nurse & $4(8 \%)$ \\
\hline
\end{tabular}

age of starting feeds, volume, type, frequency and rate of increase of feeds.

\section{Data analysis}

We present descriptive statistics as a percentage of units undertaking particular practices. We compared our data with data available from a survey presented in 2014. We assessed the linear trend of enteral feed use during TH until the end of rewarming by combining day 2 and day 3 of cooling together, using the Cochran-Armitage trend test with Monte Carlo method to reduce approximation. We used Fisher's exact test to compare the distribution of the proportion of units offering enteral feeds during $\mathrm{TH}$ between 2014 and 2016. Starting milk volumes during and post-TH were compared using Mann-Whitney $\mathrm{U}$ test. All $p$ values were two-sided, and statistical significance was defined as $\mathrm{p}<0.05$. We used XLSTAT in Microsoft Excel.

\section{RESULTS}

We approached all 69 UK neonatal units identified as offering active TH. Fifty-seven were neonatal intensive care units (NICUs) (including 20 neonatal surgical centres), and 12 were local neonatal units (LNUs). Forty-nine units responded (response rate of $71 \%$ ). Demographics of respondents are displayed in table 1 . Not all respondents felt able to answer all sections, particularly if they felt practice was variable. A lower proportion of LNUs responded $(6 / 12,50 \%)$ compared with NICUs $(43 / 57,75 \%)$. There was a wide geographical spread of responses (see online supplementary table 1 ).

\section{Enteral nutrition initiation}

Of the 49 responses, 29 units $(59 \%)$ reported starting enteral feeds during $\mathrm{TH}$ and rewarming. Of these, thirteen units $(13 / 49,27 \%)$ started feeds on day 1 , twelve units $(12 / 49,24 \%)$ on day 2 and four units $(4 / 49,8 \%)$ started feeds during rewarming. None $(0 / 49,0 \%)$ started feeds on day 3 of TH. The proportion of NICUs feeding 


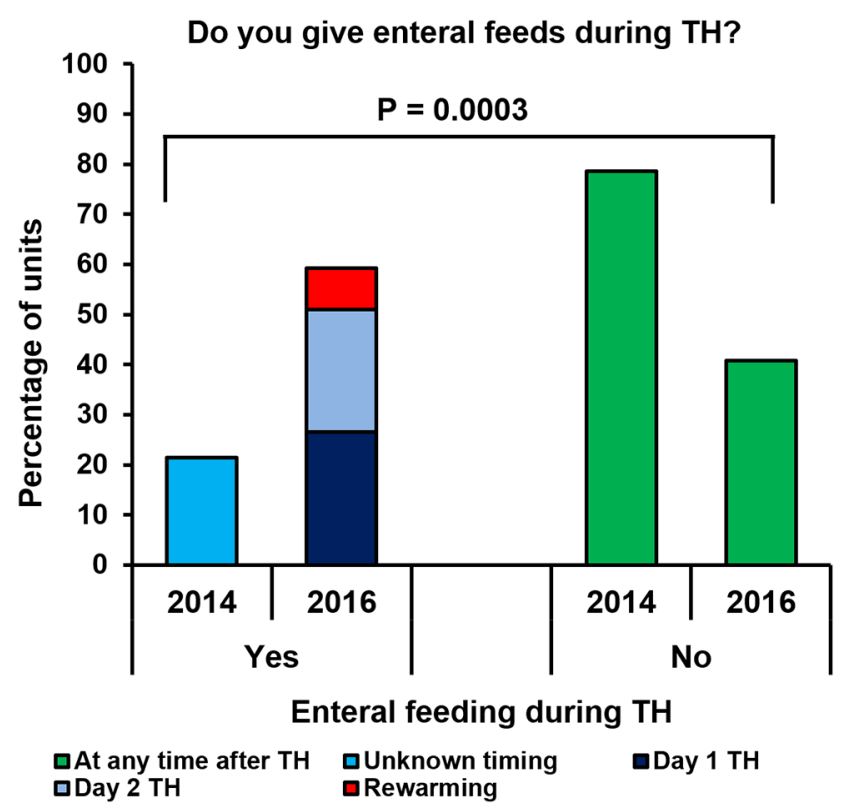

Figure 1 Comparison of rates of enteral feeding between 2014 and 2016, with day of commencement of enteral feeds for 2016 data. $\mathrm{TH}$, therapeutic hypothermia.

during $\mathrm{TH}$ was significantly higher $(59 \%, 29 / 49$ vs $21 \%$, 9/42) and NICUs not feeding were lower (41\%, 20/49 vs $79 \%, 33 / 42)(p=0.0003)$ than reported in the survey presented in 2014 (figure 1).

\section{Type of nutrition}

All units gave clear intravenous fluids, such as glucose or sodium chloride, either as drug infusions or for hydration. In addition to clear fluids, 31 units offered enteral feeds and/or PN. The types of milk and PN are shown in figure 2 .

\section{Types of enteral feeds}

Of the 29 units that offered feeds, 15 (52\%) used only EBM, 3 units (10\%) reported using DBM and EBM, while 11 units $(38 \%)$ reported that they use formula in addition to expressed and donor breast milk (figure 2).

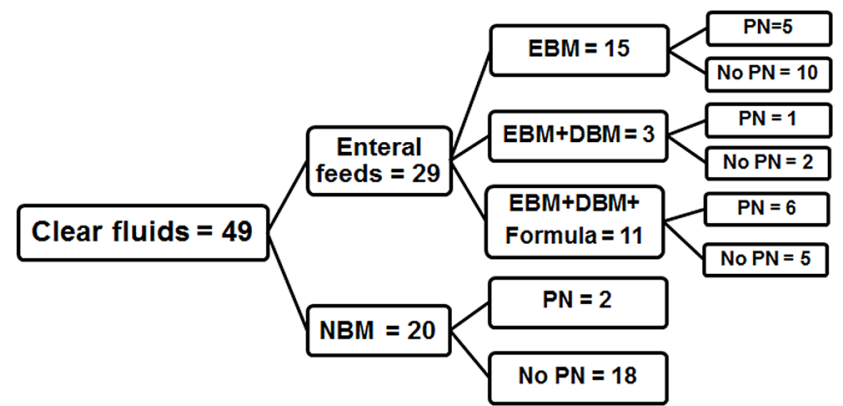

Figure 2 Types of nutrition offered by units during therapeutic hypothermia and rewarming. Clear fluids represent glucose or sodium chloride infusions either as drug infusions or for maintaining hydration. NBM represents no enteral feeding given or nil by mouth. DBM, donor breast milk; EBM, expressed breast milk; NBM, nil by mouth; PN, parenteral nutrition.

\section{Parenteral nutrition}

A total of 14 units $(14 / 49,29 \%)$ reported the routine use of PN during TH, comprising 12 units $(86 \%)$ that started enteral feeds with PN and two that did not. Eighteen units $(18 / 49,37 \%)$ provided only clear intravenous fluids, and neither feeds nor PN during TH (figure 2). Twelve units $(12 / 14,86 \%)$ used $\mathrm{PN}$ in the first 24 hours of $\mathrm{TH}$.

\section{Nutrition by day of TH and post-TH}

There was a significant linear trend for an increase in the proportion of units starting enteral feeds $(p=0.001)$ during $\mathrm{TH}$ until the end of rewarming. After rewarming, all remaining units introduced enteral feeds (figure 3A).

Feed volumes, frequency and rate of increase Starting enteral feed volumes

During cooling, the median (range) starting volume of enteral feeds was $7.5 \mathrm{~mL} / \mathrm{kg} /$ day (1.5-24), which was significantly lower than units starting feeds post-rewarming, with a median (range) of $17.5 \mathrm{~mL} / \mathrm{kg} /$ day $(7.5-30)(p=0.0004)$.

\section{Frequency of feeds}

Of the 25 units that offered enteral feeds during $\mathrm{TH}$, infants were fed 2-3 hourly in most units $(17 / 25$, $68 \%)$, hourly fed in $5 / 25(20 \%), 4-6$ hourly in $2 / 25$ $(8 \%)$ and continuously fed in $1 / 25$ (4\%). One unit giving enteral feeds during $\mathrm{TH}$ stopped feeds during rewarming. Demand feeding was more common post-rewarming, with 11 units $(11 / 49,22 \%)$ offering demand feeding $>24$ hours post-rewarming (figure $3 \mathrm{~B}$ ).

\section{Increase in feed volumes}

Of the 29 units that started feeding, 55\% (16/29) increased feeds as tolerated. Of these, 13 units (45\%) increased feeds during $\mathrm{TH}$, while $3(10 \%)$ increased feeds during rewarming. Thirteen units (13/29, 45\%) remained on static trophic feed volumes until full rewarming. Two units commented that 'reaching full feeds' during active cooling was possible, although rare. Feeds were increased 6-8 hourly post rewarming in $42 \%$ of units.

\section{Special circumstances}

Forty-seven units responded to questions regarding feeding in certain clinical situations (table 2).

Fifteen units $(31 \%)$ reported having a guideline regarding feeding during therapeutic hypothermia. Enteral feeding was variable in at least 29\% (14/49) based on the clinical condition of the baby, on-service consultant and availability of breast milk and feed tolerance; although not specifically asked, these responses mentioned variability in the free text areas.

\section{DISCUSSION}

$\mathrm{TH}$ is widely used to improve neurological outcomes for neonates with moderate-severe HIE. ${ }^{19}$ Our survey 

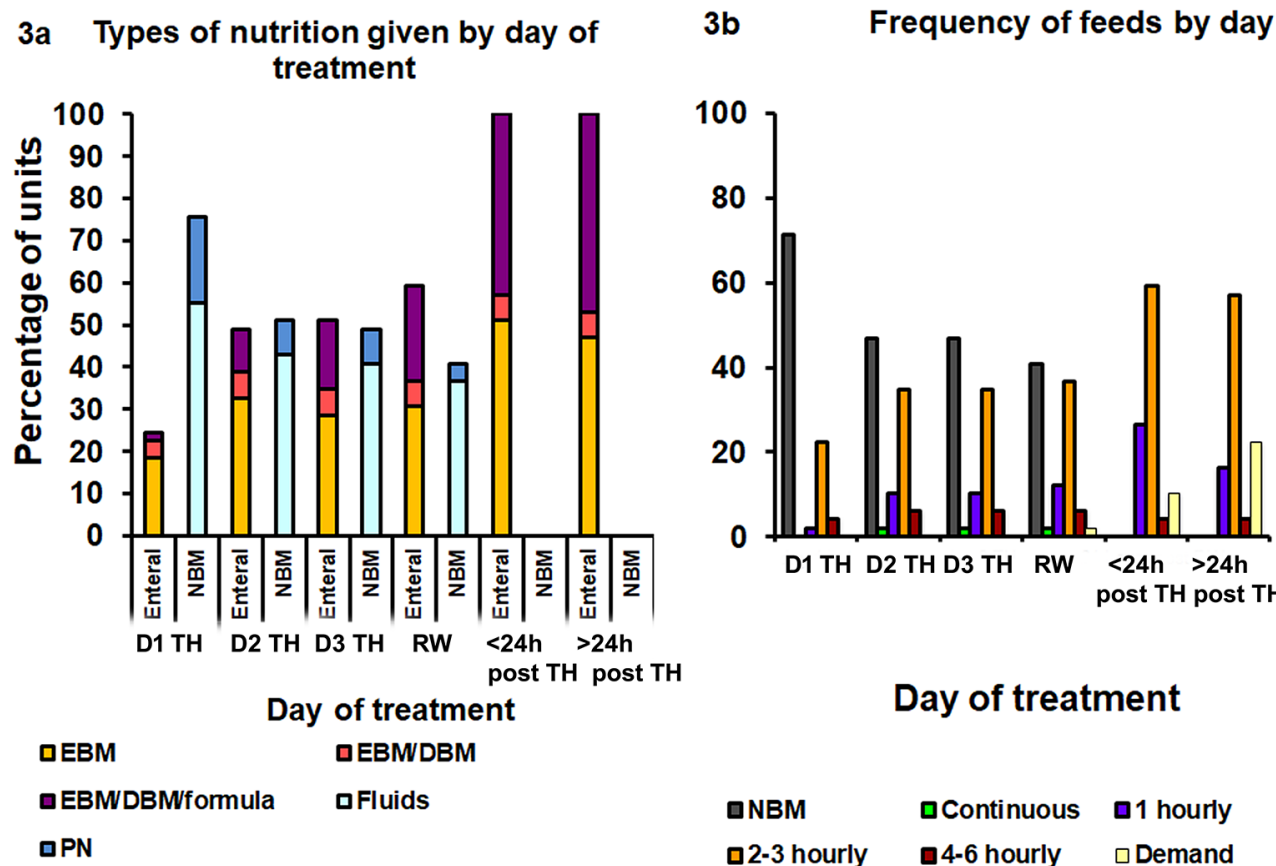

illustrates widespread variability in the use of enteral and parenteral nutrition in these infants. As compared with the survey published as an abstract in $2014,{ }^{17}$ a significantly higher proportion of units started enteral feeds during TH. Given there are 69 NICUs that offer active TH and Allen et al had contacted only 47 units, our response rate of $71 \%$ was satisfactory compared with their rate of $89 \%$. Traditionally, feeds were often withheld for a variable period in an attempt to prevent NEC following gastrointestinal ischaemia-reperfusion injury during HIE. ${ }^{20}$ We have shown that clinicians are starting small feed volumes (median $7.5 \mathrm{~mL} / \mathrm{kg} /$ day) during TH. The proportion of units not offering enteral feeds is lower than the previous survey. The effects of not offering enteral feeding or maintaining adequate nutrition with PN either on the brain recovery or gut function are unknown.

Despite adverse gut effects previously noted with HIE, moderate hypothermia has been shown to be gut-protective following ischaemia-reperfusion, ${ }^{21}{ }^{22}$ with a beneficial

Table 2 Neonatal intensive care units starting enteral feeds in certain clinical situations

\begin{tabular}{lll}
\hline Clinical situation & Yes n, \% & No n, \% \\
\hline Receiving inotropes & $16 / 47,34 \%$ & $31 / 47,66 \%$ \\
\hline Moderate HIE & $29 / 47,62 \%$ & $18 / 47,38 \%$ \\
Severe HIE & $18 / 47,38 \%$ & $29 / 47,62 \%$ \\
\hline Raised lactate (>2 mmol/L) & $28 / 47,60 \%$ & $19 / 47,40 \%$ \\
\hline
\end{tabular}

HIE, hypoxic-ischaemic encephalopathy. effect of TH on feed tolerance in neonates. ${ }^{23}$ These reports combined with increasing experience in the use of $\mathrm{TH}$, low rates of gut complications in cooled infants $(0.7 \%)^{7}$ and reports suggesting the safety of minimal enteral feeds during $\mathrm{TH}^{18}$ may have increased confidence in starting enteral feeds during TH. Clinicians were starting feeds particularly in infants with moderate HIE, with no other signs of compromise (ie, need for inotropic support). Sixty per cent offer enteral feeds when blood lactate is $>2 \mathrm{mmol} / \mathrm{L}$. High lactate is reported in cooled infants with HIE and NEC. ${ }^{24}$ The predictive ability of lactate to identify gut injury during TH merits investigation.

Breast milk and donor milk reduce the risk of NEC in preterm or low-birth-weight infants. ${ }^{25}{ }^{26}$ Although infants with HIE are at risk of developing NEC, we are not aware of data confirming maternal breast milk or DBM being protective in this group. However, observational studies report an association between the use of formula and NEC in the term population. ${ }^{27}$ It is therefore interesting to note that $38 \%$ of physicians offering feeds during TH use formula milk. Early commencement of any enteral feed may increase intestinal oxygen demand, exacerbating tissue hypoxia. During the stressful period of separation from their infant during $\mathrm{TH}$, parents perceived providing breast milk as important in an environment where they felt their contribution was small. ${ }^{28}$

Even short periods of undernutrition particularly in the setting of pre-existing brain dysfunction as in HIE might result in altered brain development, including synaptic structural changes. ${ }^{29}$ Breast milk constituents such as lactoferrin may have an impact on neurodevelopment. ${ }^{13}$ 
As $\mathrm{TH}$ does not completely ameliorate the long-term impact of HIE in all infants, ${ }^{30}$ nutrition, especially the use of breast milk, may emerge as a therapeutic adjunct.

Our survey showed that $29 \%$ of units routinely start PN, and $86 \%$ of these do so in the first 24 hours of TH. At this stage, the degree of multiorgan dysfunction and electrolyte imbalance may not be fully elucidated and may put infants at higher risk of complications such as poor lipid tolerance. ${ }^{14}$ Infants with HIE are fluid-restricted, ${ }^{16}$ and all units reported starting enteral feeds post-TH; the volume and duration of PN support are therefore likely to be limited. It is therefore difficult to know whether it is beneficial to expose infants to PN, especially as we note that $86 \%$ of units using PN also started enteral feeding. The use of PN may, however, help to ameliorate electrolyte disturbance, such as hypocalcaemia commonly seen during $\mathrm{TH}^{15}$

As this study requested individual neonatologist's opinions, and only $31 \%$ of units had guidelines regarding feeding during $\mathrm{TH}$, there may be considerable selection bias. Clinicians with a strong preference to feed during TH may have been more inclined to respond. As a survey, we were also unable to investigate the rate of gut-related complications. The perceived rapid increase in the units offering feeds during TH over the last 2 years may suggest that gut complications have remained low, as otherwise, it would seem likely that the practice of offering feeds would have been discontinued in these units. As volumes of 'trophic' feeds were not collected, the exact volumes of milk an infant may receive is not known. Majority of units did not introduce feeds in a strict ' $\mathrm{mL} / \mathrm{kg} /$ day' regimen, making a comparison of feed volumes difficult. As the survey requested individual clinician's intentions, we were unable to quantify what proportion of infants receives enteral or parenteral nutrition, the duration of $\mathrm{PN}$ provision or how variable individual practice is on surveyed units.

This national survey highlights variability within individual units, networks and nationally demonstrating considerable clinical equipoise. This variability will enable establishing the adverse effects of feeding during TH including NEC or intestinal perforation from the national and international data sets, if data are collected as to the current provision of nutrition in this group. There is enough uncertainty to make a randomised trial feasible and acceptable, but as rates of gut complications in this group are low, ${ }^{5}$ this would require large-scale recruitment. As the range of severity of illness in these infants is large, it seems likely that clinicians would have strong opinions as to whether or not feeding was suitable on an individual patient basis. This difficulty is in keeping with those faced when investigating feeding in preterm infants, and has been overcome to allow studies of early and delayed enteral feeding to be performed. The questions that need investigating include use of $\mathrm{PN}$ versus dextrose solution, minimal enteral nutrition versus NBM, expressed/donor breast milk versus formula milk, or a cluster randomised trial of different nutritional packages could be designed. Relevant outcome measures such as length of hospital stay, biomarkers of gut dysfunction such as plasma intestinal fatty acid binding protein, ${ }^{31}$ and time to full enteral feeds could be considered.

\section{CONCLUSION}

More than half of neonatal units surveyed start enteral feeding during TH. There is no consensus regarding the type, volume or frequency of enteral feeds given, or the provision of PN to these patients. In the setting of such variability, there is an urgent need to clarify the safety and benefits of the different options available to clinicians.

Contributors $\mathrm{BH}, \mathrm{BT}$ and $\mathrm{EC}$ were involved in study design, questionnaire development, data analysis and literature review. BH and MG were involved in questionnaire development and data collection. $\mathrm{BH}$ prepared first version of the manuscript. BT and EC further developed the manuscript. All authors reviewed and approved the final draft.

Competing interests None declared.

Patient consent Not required.

Provenance and peer review Not commissioned; externally peer reviewed.

Data sharing statement None.

Open Access This is an Open Access article distributed in accordance with the Creative Commons Attribution Non Commercial (CC BY-NC 4.0) license, which permits others to distribute, remix, adapt, build upon this work non-commercially, and license their derivative works on different terms, provided the original work is properly cited and the use is non-commercial. See: http://creativecommons.org/ licenses/by-nc/4.0/

(c) Article author(s) (or their employer(s) unless otherwise stated in the text of the article) 2017. All rights reserved. No commercial use is permitted unless otherwise expressly granted.

\section{REFERENCES}

1. NICE. Therapeutic hypothermia with intracorporeal temperature monitoring for hypoxic perinatal brain injury: niceipg347. $2010 \mathrm{http}: / /$ www.nice.org.uk/nicemedia/live/11315/48809/48809.pdf

2. Koç E, Arsan S, Ozcan H, et al. The effect of asphyxia on gut blood flow in term neonates. Indian J Pediatr 1998;65:297-302.

3. Ball RH, Espinoza MI, Parer JT, et al. Regional blood flow in asphyxiated fetuses with seizures. Am J Obstet Gynecol 1994;170:156-61.

4. Satas S, Løberg EM, Porter H, et al. Effect of global hypoxiaischaemia followed by $24 \mathrm{~h}$ of mild hypothermia on organ pathology and biochemistry in a newborn pig survival model. Biol Neonate 2003;83:146-56.

5. Azzopardi DV, Strohm B, Edwards AD, et al. TOBY Study Group. Moderate hypothermia to treat perinatal asphyxial encephalopathy. N Engl J Med 2009;361:1349-58.

6. Jacobs SE, Morley CJ, Inder TE, et al. Infant Cooling Evaluation Collaboration. Whole-body hypothermia for term and near-term newborns with hypoxic-ischemic encephalopathy: a randomized controlled trial. Arch Pediatr Adolesc Med 2011;165:692-700.

7. Azzopardi D, Strohm B, Linsell L, et al. UK TOBY Cooling Register. Implementation and conduct of therapeutic hypothermia for perinatal asphyxial encephalopathy in the UK--analysis of national data. PLoS One 2012;7:e38504.

8. Faingold R, Cassia G, Prempunpong C, et al. Intestinal ultrasonography in infants with moderate or severe hypoxicischemic encephalopathy receiving hypothermia. Pediatr Radiol 2016;46:87-95

9. Wilson TE, Sauder CL, Kearney ML, et al. Skin-surface cooling elicits peripheral and visceral vasoconstriction in humans. J Appl Physiol 2007;103:1257-62

10. Hall NJ, Eaton S, Peters MJ, et al. Mild controlled hypothermia in preterm neonates with advanced necrotizing enterocolitis. Pediatrics 2010;125:e300-e308.

11. Shoji H, Koletzko B. Oxidative stress and antioxidant protection in the perinatal period. Curr Opin Clin Nutr Metab Care 2007;10:324-8. 
12. Gáspárová Z, Snirc V, Stolc S, et al. Maternal treatment of rats with the new pyridoindole antioxidant during pregnacy and lactation resulting in improved offspring hippocampal resistance to ischemia in vitro. Neuro Endocrinol Lett 2010;31:348-52.

13. Wang B. Molecular determinants of milk lactoferrin as a bioactive compound in early neurodevelopment and cognition. J Pediatr 2016;173:S29-S36.

14. Ting JY, Manhas D, Innis SM, et al. Elevated triglycerides levels in two infants with hypoxic-ischemic encephalopathy undergoing therapeutic hypothermia and receiving parenteral nutrition. JPEN J Parenter Enteral Nutr 2014;38:758-60.

15. Gluckman PD, Wyatt JS, Azzopardi D, et al. Selective head cooling with mild systemic hypothermia after neonatal encephalopathy: multicentre randomised trial. Lancet 2005;365:663-70.

16. UK TOBY Cooling Register Clinician's Handbook 2010 Version 4. https://www.npeu.ox.ac.uk/./tobyregister/Register-ClinicansHandbook1-v4-07-06-1.

17. Allen G, Babarao S, Murphy A, et al. PO-0581 Nutrition during therapeutic hypothermia in neonates. Arch Dis Child 2014;99:A441-A442.

18. Thyagarajan B, Tillqvist $\mathrm{E}$, Baral $\mathrm{V}$, et al. Minimal enteral nutrition during neonatal hypothermia treatment for perinatal hypoxicischaemic encephalopathy is safe and feasible. Acta Paediatr 2015;104:146-51.

19. Jacobs SE, Berg M, Hunt R, et al. Cooling for newborns with hypoxic ischaemic encephalopathy. Cochrane Database Syst Rev 2013:CD003311

20. Akinbi H, Abbasi S, Hilpert PL, et al. Gastrointestinal and renal blood flow velocity profile in neonates with birth asphyxia. $J$ Pediatr 1994;125:625-7.

21. Stefanutti G, Pierro A, Vinardi S, et al. Moderate hypothermia protects against systemic oxidative stress in a rat model of intestinal ischemia and reperfusion injury. Shock 2005;24:159-64.
22. Hassoun HT, Kozar RA, Kone BC, et al. Intraischemic hypothermia differentially modulates oxidative stress proteins during mesenteric ischemia/reperfusion. Surgery 2002;132:369-76.

23. Thornton KM, Dai H, Septer S, et al. Effects of whole body therapeutic hypothermia on gastrointestinal morbidity and feeding tolerance in infants with hypoxic ischemic encephalopathy. Int $J$ Pediatr 2014;2014:1-7.

24. Abubacker M, Yoxall CW, Lamont G. Peri-operative blood lactate concentrations in pre-term babies with necrotising enterocolitis. Eur $J$ Pediatr Surg 2003;13:35-9.

25. Jantscher-Krenn E, Zherebtsov M, Nissan C, et al. The human milk oligosaccharide disialyllacto- $\mathrm{N}$-tetraose prevents necrotising enterocolitis in neonatal rats. Gut 2012;61:1417-25.

26. Henderson G, Anthony MY, McGuire W. Formula milk versus maternal breast milk for feeding preterm or low birth weight infants. Cochrane Database Syst Rev 2007:CD002972.

27. Maayan-Metzger A, Avivi S, Schushan-Eisen I, et al. Human milk versus formula feeding among preterm infants: short-term outcomes. Am J Perinatol 2012;29:121-6.

28. Heringhaus $\mathrm{A}$, Blom MD, Wigert $\mathrm{H}$. Becoming a parent to a child with birth asphyxia-From a traumatic delivery to living with the experience at home. Int J Qual Stud Health Well-being 2013;8:20539-13.

29. Wiggins RC, Fuller G, Enna SJ. Undernutrition and the development of brain neurotransmitter systems. Life Sci 1984;35:2085-94.

30. Lee-Kelland R, Brooks J, Tonks J, et al. Reduced sub-cortical grey matter volume is associated with functional outcome at 6-8 years in children without cerebral palsy who were cooled for hypoxic ischemic encephalopathy. San Francisco: Pediatric Academic Societies Meeting, 2017:3848. 8.

31. Schurink M, Kooi EM, Hulzebos CV, et al. Intestinal fatty acid-binding protein as a diagnostic marker for complicated and uncomplicated necrotizing enterocolitis: a prospective cohort study. PLoS One 2015;10:e0121336. 